\title{
Proteomic profiling of senescent human diploid fibroblasts treated with gamma- tocotrienol
}

\author{
Jen-Kit $\operatorname{Tan}^{*}$ (D), Faizul Jaafar and Suzana Makpol
}

\begin{abstract}
Background: Replicative senescence of human diploid fibroblasts (HDFs) has been used as a model to study mechanisms of cellular aging. Gamma-tocotrienol ( $\gamma$ T3) is one of the members of vitamin E family which has been shown to increase proliferation of senescent HDFs. However, the modulation of protein expressions by YT3 in senescent HDFs remains to be elucidated. Therefore, this study aimed to determine the differentially expressed proteins (DEPs) in young and senescent HDFs; and in vehicle- and $ү$ T3-treated senescent HDFs using label-free quantitative proteomics.

Methods: Whole proteins were extracted and digested in-gel with trypsin. Peptides were detected by Orbitrap liquid chromatography mass spectrometry. Mass spectra were identified and quantitated by MaxQuant software. The data were further filtered and analyzed statistically using Perseus software to identify DEPs. Functional annotations of DEPs were performed using Panther Classification System.

Results: A total of 1217 proteins were identified in young and senescent cells, while 1218 proteins in vehicle- and $ү$ T3treated senescent cells. 11 DEPs were found in young and senescent cells which included downregulation of plateletderived growth factor (PDGF) receptor beta and upregulation of tubulin beta-2A chain protein expressions in senescent cells. 51 DEPs were identified in vehicle- and $\gamma$ T3-treated senescent cells which included upregulation of $70 \mathrm{kDa}$ heat shock protein, triosephosphate isomerase and malate dehydrogenase protein expressions in $\gamma$ T3-treated senescent cells.

Conclusions: PDGF signaling and cytoskeletal structure may be dysregulated in senescent HDFs. The pro-proliferative effect of $Y T 3$ on senescent HDFs may be mediated through the stimulation of cellular response to stress and carbohydrate metabolism. The expressions and roles of these proteins in relation to cellular senescence are worth further investigations. Data are available via ProteomeXchange with identifier PXD009933.
\end{abstract}

Keywords: Gamma-tocotrienol, Replicative senescence, Human diploid fibroblasts, Proteomics

\section{Background}

Aging is a gradual decline in normal physiological process, often associated with age-related diseases which have negative impact on care and independence of elderly. The process of aging has been studied extensively to have a better understanding of its molecular basis in order to improve the quality of life among elderly. Human diploid fibroblasts (HDFs) cultured in vitro

\footnotetext{
* Correspondence: jenkittan@ukm.edu.my

Department of Biochemistry, Faculty of Medicine, Universiti Kebangsaan Malaysia (UKM), Jalan Yaacob Latif, Bandar Tun Razak, Cheras, 56000 Kuala Lumpur, Malaysia
}

(c) The Author(s). 2018 Open Access This article is distributed under the terms of the Creative Commons Attribution 4.0 International License (http://creativecommons.org/licenses/by/4.0/), which permits unrestricted use, distribution, and reproduction in any medium, provided you give appropriate credit to the original author(s) and the source, provide a link to the Creative Commons license, and indicate if changes were made. The Creative Commons Public Domain Dedication waiver (http://creativecommons.org/publicdomain/zero/1.0/) applies to the data made available in this article, unless otherwise stated. shortening of telomere which causes growth arrest, a phenomenon known as replicative senescence $[1,2]$. Replicative senescence of HDFs has been used as a cellular model to study the mechanism of aging. High-throughput approaches at transcriptomic and proteomic levels have been used to identify the molecular changes in senescent fibroblasts. While both approaches complement each other, proteomics have the advantage that proteins are the final gene products which can be targeted for drug design. Proteomic profiling of differentially expressed proteins (DEPs) in young and senescent fibroblasts has been 
carried out using different methods such as two-dimensional gel electrophoresis (2DGE) [3, 4], iTRAQ labeling [5], two-dimensional differential gel electrophoresis (2D-DIGE) [6]. DEPs in young and replicative senescent cells include $90 \mathrm{kDa}$ heat shock response protein (Hsp90), vimentin, collagen type I, $\alpha$-enolase, annexin and RANspecific-GTPase-activating protein $[4,5]$. These findings indicate that many pathways are altered in senescent cells which may contribute to organismal aging.

The free radical theory of aging postulates that aging is due to accumulation of free radicals over time which damages macromolecules such as nucleic acids, proteins and lipids in the body [7]. Therefore, dietary supplements which possess anti-oxidative property may ameliorate cellular aging. Vitamin $\mathrm{E}$ is a group of lipid soluble antioxidants that is consisted of 8 members, namely $\alpha-, \beta-, \gamma-$ and $\delta$-tocopherols; and $\alpha-, \beta-, \gamma$ - and $\delta$-tocotrienols [8]. While $\alpha$-tocopherol is well-studied, little is known about tocotrienols. Tocotrienol-rich fraction (TRF) has been shown to increase proliferation in senescent HDFs [9]. TRF reduces senescent-associated beta-galactosidase expression and modulates anti-oxidative enzyme activity in senescent HDFs [10]. TRF elongates telomere length and prevents cell cycle arrest in senescent HDFs [11]. One member of the tocotrienols family, gamma-tocotrienol $(\gamma \mathrm{T} 3)$, has been shown to increase proliferation of fibroblasts from young and elderly donors; and protects them from oxidative stress [12]. Our previous study shows that $\gamma \mathrm{T} 3$ increases proliferation while prevents cell cycle arrest in senescent HDFs [13]. Transcriptomic analysis reveals that $\gamma \mathrm{T} 3$ modulates expressions of genes involved in inflammation, apoptosis, protein transport and cell redox [14]. $\gamma \mathrm{T} 3$ decreases protein expressions of $\mathrm{p} 16^{\mathrm{INK} 4 \mathrm{a}}$, cyclin $\mathrm{D} 1$ and hypo-phosphorylated retinoblastoma $(\mathrm{pRb})$ in senescent HDFs [15]. Although the pro-survival effect of $\gamma \mathrm{T} 3$ on senescent HDFs has been reported, the global proteomic profile of senescent HDFs treated with $\gamma \mathrm{T} 3$ remains unclear. Understanding the mechanisms of $\gamma \mathrm{T} 3$ in promoting the proliferation of senescent HDFs may provide new insights for the modulation of $\gamma \mathrm{T} 3$ during aging. Therefore, this study applied label-free quantitative (LFQ) proteomics to detect DEPs in young and senescent HDFs; and in vehicle- and $\gamma \mathrm{T} 3$-treated senescent HDFs.

\section{Methods}

\section{Primary culture of HDFs}

Primary culture of HDFs was established from the foreskins of three 9- to 12-year-old boys. Written consents were obtained from their parents with Ethical approval code: FF-249-2012. The isolation, culture and passaging of HDFs were performed as described previously [15]. Briefly, epidermis of the skin was removed. Then, dermis was cut into small pieces, transferred into a tube with $0.03 \%$ collagenase type I solution (Worthington
Biochemical Corp, Lakewood, NJ, USA) and incubated at $37^{\circ} \mathrm{C}$ for overnight. Digested dermis was rinsed with phosphate-buffered saline and cultured in Dulbecco's Modified Eagle Medium (Gibco, Waltham, MS, USA) with $10 \%$ fetal bovine serum (Gibco) at $37^{\circ} \mathrm{C}$ in a humidified incubator with $5 \% \mathrm{CO}_{2}$. When culture reached $80-90 \%$ confluency, cells were harvested by trypsin (Gibco) and serially passaged at 1:4 expansion. The young cells were defined as having population doubling $(\mathrm{PD})<10$, while the senescent cells were at $\mathrm{PD}>55$. The proliferation rate, morphology and senescent-associated marker ( $\beta$-galactosidase) of young, senescent and $\gamma \mathrm{T} 3$-treated senescent HDFs have been characterized in previous study [13]. Senescent HDFs at PD $>55$ express $\beta$-galactosidase with flattened cellular morphology, while $\gamma \mathrm{T} 3$ increases cell proliferation and decreases cell cycle arrest of senescent HDFs. The comparisons were made between young and senescent cells; and between senescent cells treated with $\gamma \mathrm{T} 3$ and vehicle.

$5 \times 10^{5}$ cells were seeded in a $100 \mathrm{~mm}$ petri dish and allowed to grow overnight. Then, the medium was changed with fresh medium for untreated young and senescent cells, with medium containing $70 \mu \mathrm{M} \gamma \mathrm{T} 3$ or $0.1 \%$ ethanol (as vehicle) for senescent cells. After $24 \mathrm{~h}$, the cells were harvested by trypsinization. Three biological replicates were included for each group. $\gamma \mathrm{T} 3$ (>96\%) was obtained from Malaysian Palm Oil Board (MPOB, Selangor, Malaysia).

\section{Protein extraction}

Cells were lysed in RIPA buffer (Sigma-Aldrich, St. Louis, MO, USA) mixed with protease inhibitor cocktail (cOmplete, mini, EDTA-free tablet form Roche, Basel, Switzerland). Protein concentration was measured by Bradford reagent (Bio-Rad Laboratories, Hercules, CA, USA) and stored in $-80^{\circ} \mathrm{C}$ until ready to use.

\section{In-gel digestion}

In-gel digestion of protein sample was performed according to method described previously [16]. Briefly, $50 \mu \mathrm{g}$ of protein per sample was mixed with sample buffer (final concentration: $50 \mathrm{mM}$ Tris-hydrochloride at $\mathrm{pH} 6.8,2 \%$ sodium dodecyl sulfate (SDS), $10 \%$ glycerol, $0.1 \%$ bromophenol blue) and heated at $95^{\circ} \mathrm{C}$ for $10 \mathrm{~min}$. Protein sample was separated by SDS-polyacrylamide gel electrophoresis using a gel made up of 5\% stacking gel and $12 \%$ resolving gel. After electrophoresis, the gel was washed with ultrapure water (Milli-Q water; Merck Millipore, Burlington, MA, USA) for 3 times at $5 \mathrm{~min}$ each. The gel was stained with Coomassie solution (SimpleBlue SafeStain; Invitrogen, Carlsbad, CA, USA) for $1 \mathrm{~h}$ at room temperature. After staining, the gel was washed with ultrapure water for $1 \mathrm{~h}$ and washed again with ultrapure water for overnight. Each gel lane (represented 1 
sample) was cut into 6 fractions with approximately $1 \mathrm{~cm}$ length per fraction. Each fraction was cut further into smaller gel plugs of approximately $1 \mathrm{~mm}$ cube and transferred to a $2 \mathrm{~mL}$ tube. Reduction and alkylation of the gel plugs were performed as followed: incubated with $100 \%$ acetonitrile $(\mathrm{ACN})$ for $10 \mathrm{~min}, 10 \mathrm{mM}$ dithiothreitol in $100 \mathrm{mM}$ ammonium bicarbonate $(\mathrm{ABC})$ for $30 \mathrm{~min}$ at $56^{\circ}$ $\mathrm{C}$ then cooled to room temperature; followed by incubation with $55 \mathrm{mM}$ iodoacetic acid in $100 \mathrm{mM} \mathrm{ABC}$ for 20 min in dark and finally incubated with $100 \% \mathrm{ACN}$ for 10 $\mathrm{min}$. The gel plugs were destained with $50 \% \mathrm{ACN}$ in 100 $\mathrm{mM} \mathrm{ABC}$ for 30 min followed by $100 \% \mathrm{ACN}$ for $10 \mathrm{~min}$. Digestion of the proteins in gel plugs was performed with $1.33 \mathrm{ng} / \mu \mathrm{L}$ trypsin (1:30 = trypsin:protein; Trypsin Gold, mass spectrometry grade from Promega, Madison, WI, USA) in $50 \mathrm{mM} \mathrm{ABC}$ and $10 \% \mathrm{ACN}$ for overnight (>16 h) at $37^{\circ} \mathrm{C}$. After the digestion, $5 \%$ formic acid: $100 \% \mathrm{ACN}$ $(1: 2, v / v)$ was added directly to the gel plugs and incubated for $10 \mathrm{~min}$ at $37^{\circ} \mathrm{C}$ to extract peptides from the gel. Solution was transferred to a new tube and speed vacuumed for $3-4 \mathrm{~h}$ at room temperature. Dried peptides were stored at $-80{ }^{\circ} \mathrm{C}$ until use. All solutions were removed prior to addition of new solution and incubations were carried out at room temperature with shaking unless otherwise stated.

\section{Liquid chromatography tandem mass spectrometry (LCMS/MS)}

All solvents were LCMS grade purchased from Fischer Scientific (Hampton, NH, USA). Peptides from each fraction were reconstituted with $15 \mu \mathrm{L}$ mobile phase A (water $/ 0.1 \%$ formic acid) and a $6 \mu \mathrm{L}$ injection volume was drawn by Dionex Ultimate 3000 RSLCnano system (Thermo Scientific, Waltham, MA, USA) with C18 column (EASY-Spray LC column, $2 \mu \mathrm{m}$ particle size, $75 \mu \mathrm{m}$ $\mathrm{D} \times 25 \mathrm{~cm} \mathrm{~L}$; Thermo Scientific) heated at $55^{\circ} \mathrm{C}$. Gradient for nano/cap pump at a flow rate of $0.3 \mu \mathrm{L} / \mathrm{min}$ was set as followed: $5 \%$ mobile phase B (ACN $/ 0.1 \%$ formic acid) at $0 \mathrm{~min}, 7 \%$ at $5 \mathrm{~min}, 25 \%$ at $90 \mathrm{~min}, 60 \%$ at 108 min, $95 \%$ at $113-123 \mathrm{~min}, 2 \%$ at $125-135$ min. Peptides were ionized by electrospray ionization (EASY-Spray Source; Thermo Scientific) and analyzed by Q Exactive HF hybrid quadrupole-Orbitrap MS (Thermo Scientific). MS was operated at positive polarity with full MS scan (resolution: $120,000,350-1800 \mathrm{~m} / \mathrm{z}$ ) followed by data dependent $\mathrm{MS}^{2}$ scan (resolution: 15,000, normalized collision energy: 28, isolated top 20 most intense ions).

\section{Protein identification and quantification}

The mass spectral files (.RAW files) were processed using MaxQuant software (version 1.6.0.16) [17]. Default parameters were used for protein identification and quantification. Briefly, variable modification: methionine oxidation and $\mathrm{N}$-terminal acetylation; fixed modification: cysteine carbamidomethylation; enzyme: trypsin; LFQ; false discovery rate: 0.01 ; and match between run were set for searching and quantification. FASTA file of human reference proteome was downloaded from UniProt (Proteome ID UP00000640; version January 2017) [18].

\section{Statistical analysis}

The DEPs between groups were identified using Perseus software (version 1.5.4.1) [19]. LFQ intensities of proteins generated from MaxQuant were imported into Perseus. Data were pre-processed as following. Briefly, proteins identified as: only identified by site, reverse and contaminants were removed. Expression values were transformed to logarithmic scale with base 2. Samples were annotated according to their respective group. Valid values were filtered with minimum $70 \%$ presented in at least 1 group. The expressions of proteins between 2 groups were compared using 2-sample T-test with $p$ value set at $<0.05$. Principle component analysis (PCA) was performed on matrix before logarithmic transformation; multi scatter plot and histogram were constructed after filter of valid value; volcano plot was generated after 2-sample T-test; and hierarchical clustering was constructed for DEPs after calculation of z-score.

\section{Pathway analysis}

DEPs were subjected to pathway analysis using Panther Classification System online (version 13.1) [20]. Briefly, IDs: protein IDs; organism: Homo sapiens; and analysis: functional classification viewed in gene list or pie chart, were set accordingly.

The mass spectrometry proteomic data have been deposited to the ProteomeXchange Consortium via the PRIDE [21] partner repository with the dataset identifier PXD009933.

\section{Results and discussion LFQ analysis}

A total of 1878 proteins were identified through MaxQuant. After data pre-processing, 1217 proteins remained in young and senescent cells, while 1218 proteins for vehicle- and $\gamma \mathrm{T} 3$-treated senescent cells. The entire dataset was provided in Additional file 1: Table S1.

PCA showed that the samples were clustered within group and separated with other group (Additional file 2: Figure S1). Multi scatter plot showed that each sample within the comparison was highly correlated with each other with Pearson correlation, $r>0.88$; suggesting that no datasets were behaved as outliers (Additional file 2: Figure S2a \& b). The datasets were normally distributed without obvious skewness as showed in histogram (Additional file 2: Figure S2c). 
A total of 11 proteins were significantly expressed in between young and senescent cells (Table 1 and Fig. 1a \& c), while 51 DEPs were found in between vehicle- and үT3-treated senescent cells (Table 2 and Fig. 1b \& d).

\section{Gene ontology analysis}

Panther Classification System categorizes the DEPs based on their molecular function, biological process, cellular component, protein class (Additional file 2: Figures S3-S6) and pathway. The analysis showed that DEPs in between young and senescent cells belong to 4 categories of pathway which are angiogenesis, cytoskeletal regulation by Rho GTPase, Huntington disease and platelet-derived growth factor (PDGF) signaling pathway (Fig. 2a).

Based on the classification system, angiogenesis and PDGF signaling pathway are linked to PDGF receptor beta (PDGFRB) gene. PDGF is a mitogen for connective tissues such as fibroblast. It can be made up of homodimer of $\mathrm{A}, \mathrm{B}, \mathrm{C}$ and $\mathrm{D}$ polypeptide chains, and an $\mathrm{AB}$ heterodimer [22]. Its receptor, PGDFR is a type of tyrosine kinase receptor which activated upon ligand binding to form dimer, leading to a cascade of phosphorylation in pathways that promote cell growth, survival, migration and angiogenesis.

Two types of PDGFR, i.e. $\alpha$ and $\beta$ receptors (PDGFRA and PDGFRB), exist which differ in ligand-binding specificity. PDGFRA binds to all PDGF chains except D chain, whereas PDGFRB binds only to B and D chains. Thus, different PDGF dimers can induce formation of $\alpha \alpha, \alpha \beta$ or $\beta \beta$ dimeric receptor. PDGFRB mRNA level is lower in fibroblasts derived from patient with Werner

Table 1 List of differentially expressed proteins in young and senescent cells

\begin{tabular}{cl}
\hline Protein ID & Protein name (symbol) \\
\hline Qpregulated & Adenylyl cyclase-associated protein 1 (CAP1) \\
O43852 & Calumenin (CALU) \\
Q13561 & Dynactin subunit 2 (DCTN2) \\
Q92734 & Protein TFG (TFG) \\
Q9Y3A5 & Ribosome maturation protein SBDS (SBDS) \\
P09486 & SPARC (SPARC) \\
Q9NPQ8 & Synembryn-A (RIC8A) \\
Q13885 & Tubulin beta-2A chain (TUBB2A) \\
P45880 & Voltage-dependent anion-selective channel \\
& protein 2 (VDAC2) \\
Downregulated & \\
Q13308 & Inactive tyrosine-protein kinase 7 (PTK7) \\
P09619 & Platelet-derived growth factor receptor beta \\
& (PDGFRB)
\end{tabular}

Young cells were used as a control group. Proteins were sorted according to alphabetical order syndrome (a premature aging condition) compared with normal subject, suggests that lack of PDGFRB expression decreases mitogenic response of cell to PDGF [23]. In contrast, PDGFRB protein is unchanged in senescent IMR-90 cell line compared with young cells, while decreased in cells after 4 weeks into senescence [24]. Similarly, there is no difference of PDGFRB protein expression in senescent and young cells of both human embryonic lung fibroblast IMR-90 and WI-38 cell lines [25]. Taken together, these findings suggest that PDGFRB protein expression may reduce only after a prolong culture of senescent cells. In this study, senescent cells were cultured for more than a week to be confluent before used for experiment. Our results showed that PDGFRB protein expression was downregulated in senescent cells compared with young cells. Our findings suggest that one of the mechanisms of replicative senescence may due to decrease level of growth factor receptor which leads to a reduced response to mitogenic stimuli and eventually diminishes the proliferative signaling pathways in senescent cells.

On the other hand, pathways in cytoskeletal regulation by Rho GTPase and Huntington disease are linked to tubulin beta-2A chain $(T U B B 2 A)$ gene. $\beta$-tubulin interacts with mutant huntingtin protein which leads to impairment of intracellular transport [26]. Rho GTPase modulates dynamics and polarization of microtubules. Microtubules are mainly consisted of $\alpha$ - and $\beta$-tubulin heterodimers [27]. Protein level of tubulin beta- 3 chain is higher in keratinocyte cells established from elderly donors than young donors, indicates that it may be a biomarker for skin aging [28]. In this study, TUBB2A protein expression was upregulated in senescent cells compared to young cells. However, the roles of TUBB2A in replicative senescence involving those two pathways are poorly understood.

For comparison between vehicle- and $\gamma$ T3-treated senescent cells in this study, the DEPs belong to 35 categories of pathway such as gonadotropin-releasing hormone receptor pathway, apoptosis signaling pathway, Parkinson disease, glycolysis and pyruvate metabolism (Fig. 2b).

Aging is associated with decrease in stress response which leads to accumulation of damaged proteins. Heat shock response is the primordial defense mechanism against stressful conditions. This response is modulated by a family of Hsp, such as $70 \mathrm{kDa} H s p$ (Hsp70), which assists in folding of new proteins and directs refolding or degradation of misfolded proteins that are often associated with neurodegenerative disease [29]. Hsp70 prolongs lifespan and improves cognitive function of aging mice [30]. In this study, Hsp70 was upregulated in $\gamma$ T3-treated senescent cells compared with vehicletreated senescent cells. Our results suggest that $\gamma \mathrm{T} 3$ may 


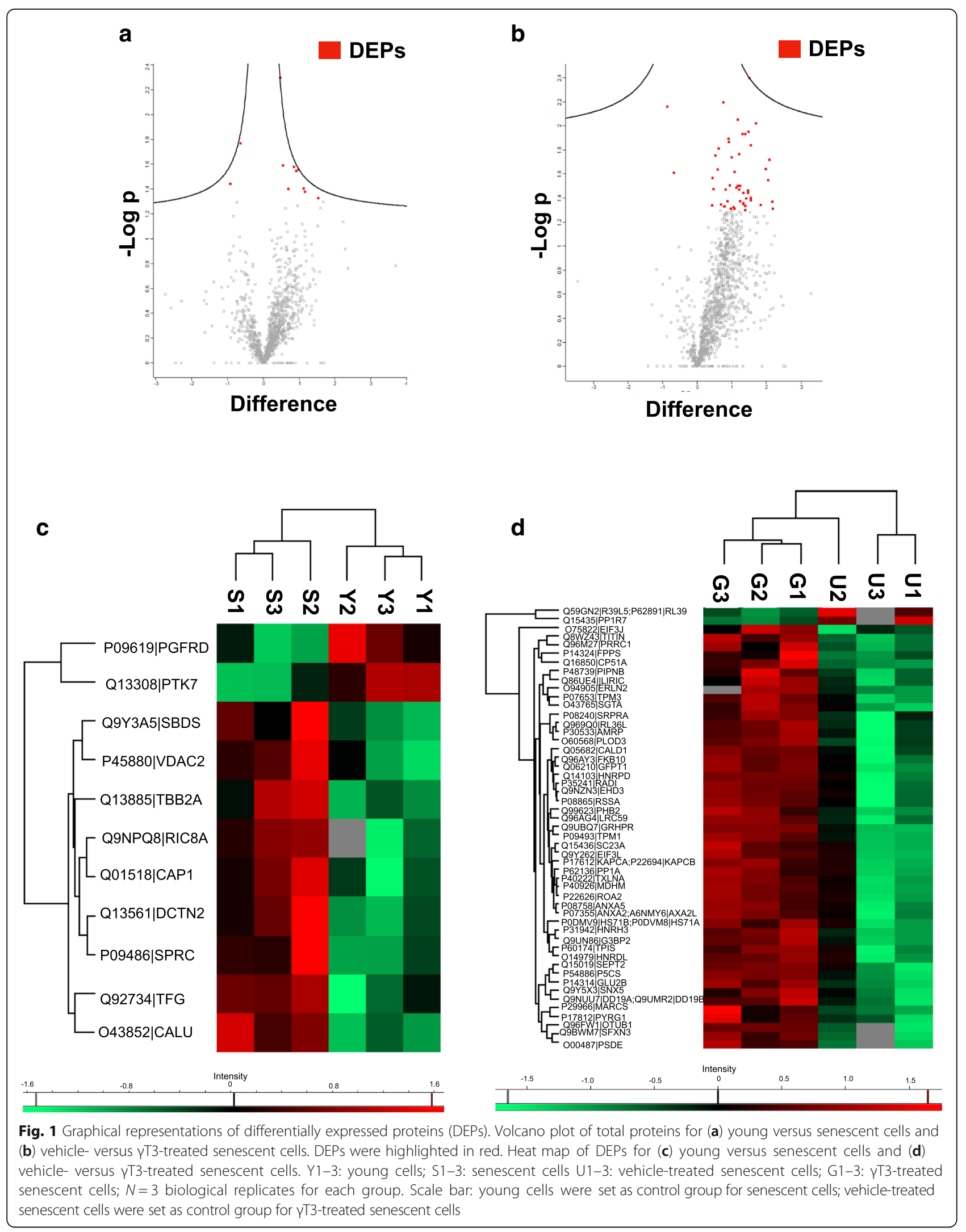


Table 2 List of differentially expressed proteins in vehicle- and YT3-treated senescent cells

\begin{tabular}{|c|c|}
\hline Protein ID & Protein name (symbol) \\
\hline \multicolumn{2}{|l|}{ Upregulated } \\
\hline 000487 & $\begin{array}{l}265 \text { proteasome non-ATPase regulatory } \\
\text { subunit } 14 \text { (PSMD14) }\end{array}$ \\
\hline P08865 & 40 S ribosomal protein SA (RPSA) \\
\hline Q969Q0 & $60 S$ ribosomal protein L36a-like (RPL36AL) \\
\hline P30533 & $\begin{array}{l}\text { Alpha-2-macroglobulin receptor-associated } \\
\text { protein (LRPAP1) }\end{array}$ \\
\hline P40222 & Alpha-taxilin (TXLNA) \\
\hline P07355;A6NMY6 & $\begin{array}{l}\text { Annexin A2 (ANXA2); } \\
\text { Putative annexin A2-like protein (ANXA2P2) }\end{array}$ \\
\hline P08758 & Annexin A5 (ANXA5) \\
\hline Q9NUU7;Q9UMR2 & $\begin{array}{l}\text { ATP-dependent RNA helicase DDX19A (DDX19A); } \\
\text { ATP-dependent RNA helicase DDX19B (DDX19B) }\end{array}$ \\
\hline Q05682 & Caldesmon (CALD1) \\
\hline P17612;P22694 & $\begin{array}{l}\text { CAMP-dependent protein kinase catalytic subunit } \\
\text { alpha (PRKACA); } \\
\text { CAMP-dependent protein kinase catalytic subunit } \\
\text { beta (PRKACB) }\end{array}$ \\
\hline P17812 & CTP synthase 1 (CTPS1) \\
\hline P54886 & $\begin{array}{l}\text { Delta-1-pyrroline-5-carboxylate synthase } \\
\text { (ALDH18A1) }\end{array}$ \\
\hline Q9NZN3 & EH domain-containing protein 3 (EHD3) \\
\hline O94905 & Erlin-2 (ERLIN2) \\
\hline O75822 & $\begin{array}{l}\text { Eukaryotic translation initiation factor } 3 \text { subunit } \\
\mathrm{J}(\text { (EIF3J) }\end{array}$ \\
\hline Q9Y262 & $\begin{array}{l}\text { Eukaryotic translation initiation factor } 3 \text { subunit } \\
\mathrm{L} \text { (EIF3L) }\end{array}$ \\
\hline P14324 & Farnesyl pyrophosphate synthase (FDPS) \\
\hline P14314 & Glucosidase 2 subunit beta (PRKCSH) \\
\hline Q06210 & $\begin{array}{l}\text { Glutamine--fructose-6-phosphate aminotransferase } \\
\text { [isomerizing] } 1 \text { (GFPT1) }\end{array}$ \\
\hline Q9UBQ7 & $\begin{array}{l}\text { Glyoxylate reductase/hydroxypyruvate reductase } \\
\text { (GRHPR) }\end{array}$ \\
\hline PODMV9;PODMV8 & $\begin{array}{l}\text { Heat shock } 70 \mathrm{kDa} \text { protein } 1 \mathrm{~B} \text { (HSPA71B); } \\
\text { Heat shock } 70 \mathrm{kDa} \text { protein } 1 \mathrm{~A}(\mathrm{HSPA} 71 \mathrm{~A})\end{array}$ \\
\hline Q14103 & $\begin{array}{l}\text { Heterogeneous nuclear ribonucleoprotein } \\
\text { D0 (HNRNPD) }\end{array}$ \\
\hline 014979 & $\begin{array}{l}\text { Heterogeneous nuclear ribonucleoprotein } \\
\text { D-like (HNRNDL) }\end{array}$ \\
\hline P31942 & $\begin{array}{l}\text { Heterogeneous nuclear ribonucleoprotein } \mathrm{H} 3 \\
\text { (HNRNH3) }\end{array}$ \\
\hline P22626 & $\begin{array}{l}\text { Heterogeneous nuclear ribonucleoproteins } \\
\text { A2/B1 (HNRNPA2B1) }\end{array}$ \\
\hline Q16850 & Lanosterol 14-alpha demethylase (CYP51A1) \\
\hline Q96AG4 & $\begin{array}{l}\text { Leucine-rich repeat-containing protein } 59 \\
\text { (LRRC59) }\end{array}$ \\
\hline P40926 & Malate dehydrogenase, mitochondrial (MDH2) \\
\hline P29966 & $\begin{array}{l}\text { Myristoylated alanine-rich C-kinase substrate } \\
\text { (MARCKS) }\end{array}$ \\
\hline Q96AY3 & Peptidyl-prolyl cis-trans isomerase FKBP10 \\
\hline
\end{tabular}

Table 2 List of differentially expressed proteins in vehicle- and YT3-treated senescent cells (Continued)

\begin{tabular}{|c|c|}
\hline Protein ID & Protein name (symbol) \\
\hline & (FKBP10) \\
\hline P48739 & $\begin{array}{l}\text { Phosphatidylinositol transfer protein beta } \\
\text { isoform (PITPNB) }\end{array}$ \\
\hline O60568 & $\begin{array}{l}\text { Procollagen-lysine,2-oxoglutarate 5-dioxygenase } \\
3 \text { (PLOD3) }\end{array}$ \\
\hline Q99623 & Prohibitin-2 (PHB2) \\
\hline Q86UE4 & Protein LYRIC (MTDH) \\
\hline Q96M27 & Protein PRRC1 (PRRC1) \\
\hline Q15436 & Protein transport protein Sec23A (SEC23A) \\
\hline P35241 & Radixin (RDX) \\
\hline Q9UN86 & $\begin{array}{l}\text { Ras GTPase-activating protein-binding protein } \\
2 \text { (G3BP2) }\end{array}$ \\
\hline Q15019 & Septin-2 (SEPT2) \\
\hline P62136 & $\begin{array}{l}\text { Serine/threonine-protein phosphatase PP1-alpha } \\
\text { catalytic subunit (PPP1CA) }\end{array}$ \\
\hline Q9BWM7 & Sideroflexin-3 (SFXN3) \\
\hline P08240 & $\begin{array}{l}\text { Signal recognition particle receptor subunit alpha } \\
\text { (SRPRA) }\end{array}$ \\
\hline O43765 & $\begin{array}{l}\text { Small glutamine-rich tetratricopeptide repeat- } \\
\text { containing protein alpha (SGTA) }\end{array}$ \\
\hline Q9Y5X3 & Sorting nexin-5 (SNX5) \\
\hline Q8WZ42 & Titin (TTN) \\
\hline P60174 & Triosephosphate isomerase (TPI1) \\
\hline P09493 & Tropomyosin alpha-1 chain (TPM1) \\
\hline P06753 & Tropomyosin alpha-3 chain (TPM3) \\
\hline Q96FW1 & Ubiquitin thioesterase (OTUB1) \\
\hline \multicolumn{2}{|l|}{ Downregulated } \\
\hline Q15435 & $\begin{array}{l}\text { Protein phosphatase } 1 \text { regulatory subunit } 7 \\
\text { (PPP1R7) }\end{array}$ \\
\hline Q59GN2;P62891 & $\begin{array}{l}\text { Putative } 60 \text { S ribosomal protein L39-like } 5 \\
\text { (RPL39P5); } \\
60 S \text { ribosomal protein L39 (RPL39) }\end{array}$ \\
\hline
\end{tabular}

Vehicle-treated senescent cells were used as a control group. Proteins were sorted according to alphabetical order

increase the stress response of senescent cells which accounts for its pro-survival effect on senescent cells as observed in previous study [15]. Cells isolated from aged organisms or undergoing replicative senescence have reduced heat shock response. Hsp70 protein level is higher in late passage of IMR-90 cells than early passage cells; and in fibroblasts isolated from elderly donors than young donors [31]. However, our results did not indicate a difference for Hsp70 expression in young and senescent cells. The reason for the discordant findings is unclear. In addition, due to the highly homologous sequences, Maxquant analysis could not differentiate members of Hsp70 family and could only annotate the detected protein group as either Hsp70-1a (gene name: HSPA1A) or Hsp70-1b (gene: HSPA1B) homolog. Further 
a

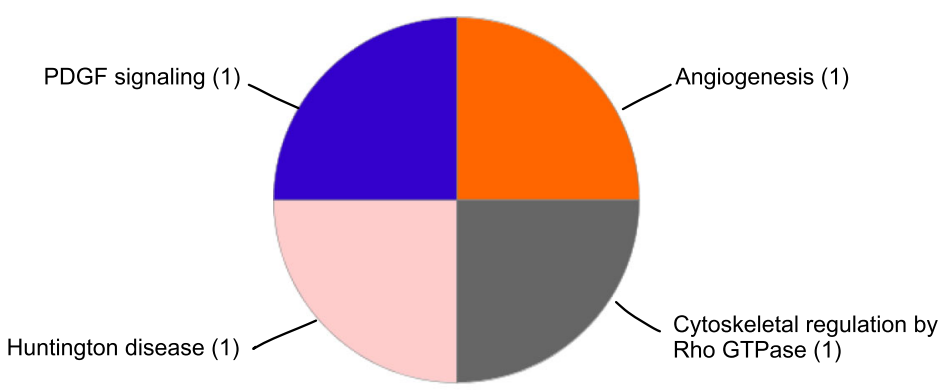

b

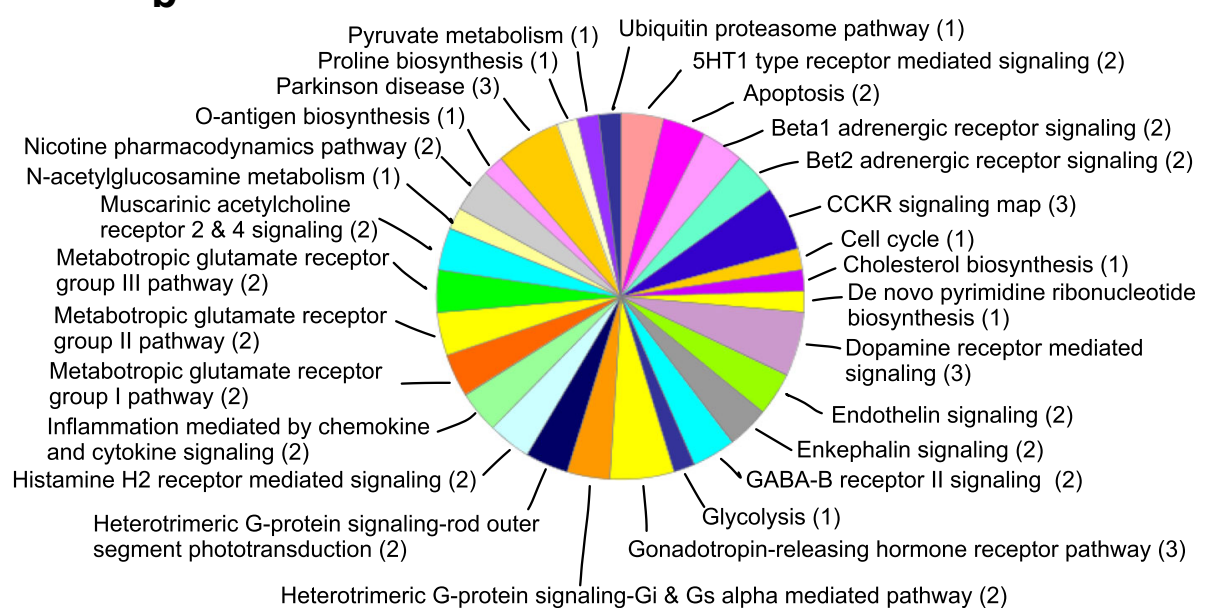

Fig. 2 Distribution of pathways based on Panther Classification System. Pathways related to differentially expressed proteins in (a) young versus senescent cells and (b) vehicle- versus $\gamma$ T3-treated senescent cells. The number in bracket indicates number of proteins

studies are needed to investigate the role of Hsp70 in senescence and determine which homolog is involved in the modulation using methods such as qPCR or immunoblotting with specific antibodies.

Caloric restriction (CR) has been shown as an effective way to prolong lifespan across many species, including human [32]. Carbohydrate metabolism is closely related to $\mathrm{CR}$ indicating the important role of energy metabolism during aging. Abnormal carbohydrate metabolisms are observed in cellular senescence which involve enzymes in glycolysis, tricarboxylic acid (TCA) cycle and malate-aspartate shuttle [33]. Triosephosphate isomerase (TPI) is a key enzyme in glycolysis and its deficiency causes accumulation of dihydroxyacetone phosphate which inhibits glycolysis [34]. Although it is a rare genetic disease, TPI deficiency is a progressive neurodegenerative condition closely resembles Alzheimer disease. TPI activity is decreased while its protein expression is unchanged with age in hippocampus of senescence accelerated mouse model, and increase of TPI activity by acupuncture intervention is accompanied with improvement of cognitive performance; suggesting that abnormal glucose metabolism is related to aging and dementia [35]. Our results showed that TPI protein expression was increased in senescent cells treated with $\gamma \mathrm{T} 3 \mathrm{com}$ pared with vehicle-treated cells, suggesting that $\gamma \mathrm{T} 3$ may promote the glycolysis of senescent cells.

Malate-aspartate shuttle translocates NADH produced from glycolysis into matrix of mitochondria for ATP production via oxidative phosphorylation [36]. One of the key enzymes in this shuttle is malate dehydrogenase $(\mathrm{MDH})$ which presents in two major forms: cytosolic $\mathrm{MDH}$ (MDH1) and mitochondrial MDH (MDH2), together they catalyze the interconversion of malate and oxaloacetate. MDH1 catalyzes the reduction of oxaloacetate to malate. MDH2, which is also part of TCA cycle, catalyzes the oxidation of malate to oxaloacetate. MDH1 activity and protein level are lower in senescent HDFs [37]. Furthermore, knockdown of MDH1 in young HDFs and IMR-90 cells induces senescence, while knockdown 
of MDH2 has no effect on cellular senescence of young HDFs. These findings indicate that MDH1 plays a critical role in regulating cellular senescence. In this study, $\mathrm{MDH} 2$ protein expression was higher in senescent cells treated with $\gamma \mathrm{T} 3$ compared with untreated cells. Although MDH2 may not be directly regulating cellular senescence, it may still affect the energy metabolism as it is part of the shuttle. Increase of $\mathrm{MDH} 2$ protein level by $\gamma \mathrm{T} 3$ suggests that $\gamma \mathrm{T} 3$ may modulating the malate-aspartate shuttle and TCA cycle in senescent cells. Taken together, our results suggest that $\gamma \mathrm{T} 3$ may promote survival of senescent cells by increasing carbohydrate metabolism that involves in glycolysis and malate-aspartate shuttle. However, one should be cautious when interpreting protein expressions of enzymes as their functionality would be better indicated by enzymatic activity. In addition, our DEPs results are different from previous studies $[4,5,15]$ which show no change in expressions of proteins such as $\mathrm{p} 16^{\mathrm{INK4a}}$, cyclin $\mathrm{D} 1$ and $\mathrm{pRb}$. This may due to the difference in (1) detection platforms such as immunoblotting, 2DGE, or label and unlabeled LCMS; (2) cell types used such as primary culture of HDFs or cell lines; and (3) post-translational modifications of protein such as performing phosphoproteome or whole proteome extraction. Further studies are required to investigate the role of these enzymes on energy metabolism during aging. Our previous study on transcriptomic profiling of senescent HDFs shows that $\gamma \mathrm{T} 3$ upregulates mRNA expression of Hsp70 member 5 (gene: HSPA5) which involves in response to stress; and upregulates mRNA expression of mitochondrial alanine transaminase (gene: GPT2) which involves in carbohydrate and amino acid metabolisms [14]. Our transcriptomic and proteomic data show the same pathways are modulated by $\gamma \mathrm{T} 3$ on senescent HDFs but the expression of mRNA is not in concordance with its protein expression. This may due to the difference in expression timing for mRNA and protein of the same gene. Future studies on integrating the data from transcriptomic and proteomic studies may provide more comprehensive view and new insights for understanding the mechanisms of cellular senescence and the modulation of senescence by $\gamma \mathrm{T} 3$.

\section{Conclusions}

LFQ proteomic analysis in this study showed that PDGFRB protein level was lower and TUBB2A protein level was higher in senescent HDFs than young cells, suggesting that pathways such as growth factor signaling and cytoskeletal regulation may be dysregulated during cellular senescence. On the other hand, protein levels of Hsp70, TPI and MDH2 were higher in $\gamma \mathrm{T} 3$-treated senescent HDFs than vehicle-treated cells, suggesting that modulation of cellular senescence by $\gamma \mathrm{T} 3$ may involve the stimulation of stress response and carbohydrate metabolism. The roles of these proteins in regulating cellular senescence worth further investigations.

\section{Additional files}

Additional file 1: Table S1. Protein lists for the datasets. (XLSX $111 \mathrm{~kb}$ )

Additional file 2: Figure S1-S6. Showing the statistical and gene ontology analyses of the datasets. (PDF $443 \mathrm{~kb}$ )

\section{Abbreviations}

2DGE: Two dimensional gel electrophoresis; ABC: Ammonium bicarbonate; ACN: Acetonitrile; CR: Caloric restriction; DEPs: Differentially expressed proteins; HDFs: Human diploid fibroblasts; Hsp: Heat shock response protein; LCMS/MS: Liquid chromatography tandem mass spectrometry; LFQ: Labelfree quantitative; $\mathrm{MDH}$ : Malate dehydrogenase; PCA: Principle component analysis; PD: Population doubling; PDGF(R): Platelet-derived growth factor (receptor); pRb: Phosphorylated retinoblastoma protein; SDS: Sodium dodecyl sulfate; TCA: Tricarboxylic acid; TPI: Triosephosphate isomerase; TRF: Tocotrienol-rich fraction; TUBB2A: Tubulin beta-2A chain; үT3: Gammatocotrienol

\section{Acknowledgments}

We would like to thank all the participants and their family for their collaboration. We would like to acknowledge Zulzikry Hafiz Abu Bakar for advice on data analysis. We thank MPOB for providing $\gamma T 3$.

\section{Funding}

This work was financially supported by Dana Impak Perdana (DIP-2013-003 \& DIP-2015-004). The funding sponsors had no role in the design of the study and collection, analysis, and interpretation of data and in writing the manuscript.

Availability of data and materials

The mass spectrometry proteomic data have been deposited to the ProteomeXchange Consortium via the PRIDE [21] partner repository with the dataset identifier PXD009933.

\section{Author's contributions}

JT and SM designed the study. FJ and JT performed the experiment. JT conducted the data analysis and interpretation. JT drafted the manuscript. All authors read and approved the final manuscript.

\section{Ethics approval and consent to participate}

Ethical approval was obtained from UKM Ethical Committee with the approval code: FF-249-2012. Sample collection was conducted according to the UKM Guidelines for Ethical Review of Clinical Research or Research Involving Human subjects 2014. Written informed consent was provided to the participants' parents.

Consent for publication

Not applicable.

\section{Competing interests}

The authors declare that they have no competing interests.

\section{Publisher's Note}

Springer Nature remains neutral with regard to jurisdictional claims in published maps and institutional affiliations.

Received: 3 May 2018 Accepted: 22 November 2018 Published online: 29 November 2018

\section{References}

1. Hayflick L. The limited in vitro lifetime of human diploid cell strains. Exp Cell Res. 1965;37(3):614-36. 
2. Allsopp RC, Vaziri H, Patterson C, Goldstein S, Younglai EV, Futcher AB, et al. Telomere length predicts replicative capacity of human fibroblasts. Proc Natl Acad Sci U S A. 1992;89(21):10114-8.

3. Goon JA, Ahmad Hairi H, Makpol S, Abdul Rahman M, Karsani SA, Wan Ngah WZ. Differential protein expression in senescent human skin fibroblasts and stress induced premature senescence (SIPS) fibroblasts. Sains Malaysiana. 2011;40(11):1247-53.

4. Trougakos IP, Saridaki A, Panayotou G, Gonos ES. Identification of differentially expressed proteins in senescent human embryonic fibroblasts. Mech Ageing Dev. 2006;127(1):88-92.

5. Cong YS, Fan E, Wang E. Simultaneous proteomic profiling of four different growth states of human fibroblasts, using amine-reactive isobaric tagging reagents and tandem mass spectrometry. Mech Ageing Dev. 2006;127(4): 332-43.

6. Hammad G, Legrain Y, Touat-Hamici Z, Duhieu S, Cornu D, Bulteau AL, et al. Interplay between selenium levels and replicative senescence in WI-38 human fibroblasts: a proteomic approach. Antioxidants. 2018;7(1):19.

7. Harman D. Aging: a theory based on free radical and radiation chemistry. J Gerontol. 1956;11(3):298-300.

8. Sen CK, Khanna S, Roy S. Tocotrienols: vitamin E beyond tocopherols. Life Sci. 2006;78(18):2088-98.

9. Goon JA, Mohd Adi M, Ahmad Hairi H. Tocotrienol rich fraction (TRF) increases viability of senescent fibroblast. Research Updates in Medical Sciences. 2013;1 (2):3-6.

10. Makpol S, Yeoh TW, Ruslam FA, Arifin KT, Yusof YA. Comparative effect of Piper betle, Chlorella vulgaris and tocotrienol-rich fraction on antioxidant enzymes activity in cellular ageing of human diploid fibroblasts. BMC Complement Altern Med. 2013;13:210.

11. Makpol S, Durani LW, Chua KH, Mohd Yusof YA, Ngah WZ. Tocotrienol-rich fraction prevents cell cycle arrest and elongates telomere length in senescent human diploid fibroblasts. J Biomed Biotechnol. 2011;2011: 506171.

12. Makpol S, Abidin AZ, Sairin K, Mazlan M, Top GM, Ngah WZ. Gammatocotrienol prevents oxidative stress-induced telomere shortening in human fibroblasts derived from different aged individuals. Oxidative Med Cell Longev. 2010;3(1):35-43.

13. Makpol S, Zainuddin A, Chua KH, Yusof YA, Ngah WZ. Gamma-tocotrienol modulation of senescence-associated gene expression prevents cellular aging in human diploid fibroblasts. Clinics. 2012;67(2):135-43.

14. Makpol S, Zainuddin A, Chua KH, Mohd Yusof YA, Ngah WZ. Gammatocotrienol modulated gene expression in senescent human diploid fibroblasts as revealed by microarray analysis. Oxidative Med Cell Longev. 2013;2013:454328.

15. Zainuddin A, Chua KH, Tan JK, Jaafar F, Makpol S. Gamma-tocotrienol prevents cell cycle arrest in aged human fibroblast cells through p16(INK4a) pathway. J Physiol Biochem. 2017;73(1):59-65.

16. Shevchenko A, Tomas H, Havlis J, Olsen JV, Mann M. In-gel digestion for mass spectrometric characterization of proteins and proteomes. Nat Protoc. 2006;1(6):2856-60

17. Cox J, Mann M. MaxQuant enables high peptide identification rates, individualized p.p.b.-range mass accuracies and proteome-wide protein quantification. Nat Biotechnol. 2008;26(12):1367-72.

18. The UniProt C. UniProt: the universal protein knowledgebase. Nucleic Acids Res. 2017:45(D1):D158-D69.

19. Tyanova S, Temu T, Sinitcyn P, Carlson A, Hein MY, Geiger T, et al. The Perseus computational platform for comprehensive analysis of (prote)omics data. Nat Methods. 2016;13(9):731-40

20. Thomas PD, Campbell MJ, Kejariwal A, Mi H, Karlak B, Daverman R, et al. PANTHER: a library of protein families and subfamilies indexed by function. Genome Res. 2003;13(9):2129-41.

21. Vizcaino JA, Csordas A, Del-Toro N, Dianes JA, Griss J, Lavidas I, et al. 2016 update of the PRIDE database and its related tools. Nucleic Acids Res. 2016; 44(22):11033.

22. Heldin $\mathrm{CH}$, Lennartsson J. Structural and functional properties of plateletderived growth factor and stem cell factor receptors. Cold Spring Harb Perspect Biol. 2013;5(8):a009100.

23. Mori S, Kawano M, Kanzaki T, Morisaki N, Saito Y, Yoshida S. Decreased expression of the platelet-derived growth factor beta-receptor in fibroblasts from a patient with Werner's syndrome. Eur J Clin Investig. 1993;23(3):161-5.
24. Chen JH, Ozanne SE, Hales CN. Analysis of expression of growth factor receptors in replicatively and oxidatively senescent human fibroblasts. FEBS Lett. 2005;579(28):6388-94.

25. Li Q, Bai L, Liu N, Wang M, Liu JP, Liu P, et al. Increased polymerase I and transcript release factor (Cavin-1) expression attenuates platelet-derived growth factor receptor signalling in senescent human fibroblasts. Clin Exp Pharmacol Physiol. 2014;41(3):169-73.

26. Smith R, Bacos $K$, Fedele $V$, Soulet $D$, Walz HA, Obermuller $S$, et al. Mutant huntingtin interacts with \{beta\}-tubulin and disrupts vesicular transport and insulin secretion. Hum Mol Genet. 2009;18(20):3942-54.

27. Herve JC, Bourmeyster N. Rho GTPases at the crossroad of signaling networks in mammals. Small GTPases. 2015;6(2):43-8.

28. Lehmann SG, Bourgoin-Voillard S, Seve M, Rachidi W. Tubulin beta-3 chain as a new candidate protein biomarker of human skin aging: a preliminary study. Oxidative Med Cell Longev. 2017:2017:5140360.

29. Lackie RE, Maciejewski A, Ostapchenko VG, Marques-Lopes J, Choy WY, Duennwald ML, et al. The Hsp70/Hsp90 chaperone machinery in neurodegenerative diseases. Front Neurosci. 2017;11:254.

30. Bobkova NV, Evgen'ev M, Garbuz DG, Kulikov AM, Morozov A, Samokhin A, et al. Exogenous Hsp70 delays senescence and improves cognitive function in aging mice. Proc Natl Acad Sci U S A. 2015;112(52):16006-11.

31. Gutsmann-Conrad A, Heydari AR, You S, Richardson A. The expression of heat shock protein 70 decreases with cellular senescence in vitro and in cells derived from young and old human subjects. Exp Cell Res. 1998;241(2): 404-13.

32. Anderson RM, Weindruch R. Metabolic reprogramming, caloric restriction and aging. Trends Endocrinol Metab. 2010;21(3):134-41.

33. Wiley CD, Campisi J. From ancient pathways to aging cells-connecting metabolism and cellular senescence. Cell Metab. 2016;23(6):1013-21.

34. Orosz F, Olah J, Ovadi J. Triosephosphate isomerase deficiency: new insights into an enigmatic disease. Biochim Biophys Acta. 2009;1792(12):1168-74.

35. Zhao L, Jia Y, Yan D, Zhou C, Han J, Yu J. Aging-related changes of triose phosphate isomerase in hippocampus of senescence accelerated mouse and the intervention of acupuncture. Neurosci Lett. 2013;542:59-64.

36. Ziegler DV, Wiley CD, Velarde MC. Mitochondrial effectors of cellular senescence: beyond the free radical theory of aging. Aging Cell. 2015; 14(1):1-7.

37. Lee SM, Dho SH, Ju SK, Maeng JS, Kim JY, Kwon KS. Cytosolic malate dehydrogenase regulates senescence in human fibroblasts. Biogerontology. 2012;13(5):525-36.

\section{Ready to submit your research? Choose BMC and benefit from:}

- fast, convenient online submission

- thorough peer review by experienced researchers in your field

- rapid publication on acceptance

- support for research data, including large and complex data types

- gold Open Access which fosters wider collaboration and increased citations

- maximum visibility for your research: over $100 \mathrm{M}$ website views per year

At BMC, research is always in progress.

Learn more biomedcentral.com/submissions 